\title{
Adsorption Behaviors of Oxytetracycline onto Sediment in the Weihe River, Shaanxi, China
}

\author{
Dong-Hui Cheng, Sheng-Ke Yang, Yue Zhao, and Jing Chen \\ The Key Laboratory of Subsurface Hydrology and Ecology in Arid Areas, School of Environmental Science and Engineering, \\ Chang'an University, 126 Yanta Road, Yanta District, Xian 710054, China \\ Correspondence should be addressed to Sheng-Ke Yang; ysk110@126.com
}

Received 18 December 2012; Revised 10 March 2013; Accepted 21 March 2013

Academic Editor: Rosario Rodil Rodríguez

Copyright (C) 2013 Dong-Hui Cheng et al. This is an open access article distributed under the Creative Commons Attribution License, which permits unrestricted use, distribution, and reproduction in any medium, provided the original work is properly cited.

\begin{abstract}
Adsorption behaviors of oxytetracycline onto sediment in the Weihe River were described. The impact factors in the processes of adsorption, such as contact time, solution $\mathrm{pH}$, temperature, and ionic strength, were determined by experiments. The experimental results were analyzed by kinetic and isotherm models. The adsorption kinetics was found to follow a pseudo-first-order model. The equilibrium adsorption data fitted well with the Langmuir and Freundlich isotherm models. However, the Langmuir isotherm was more suitable to describe the adsorption. Thermodynamics parameters such as Gibbs-free energy change $\left(\Delta G^{\circ}\right)$, enthalpy change $\left(\Delta H^{\circ}\right)$, and entropy change $\left(\Delta S^{\circ}\right)$ were calculated. Results showed that the adsorption was feasible, spontaneous, entropy increasing, and endothermic in nature, which reached equilibrium in about 24 hours. The adsorption capacity did not cause obvious change at solution $\mathrm{pH} 4.0-7.0$, and both decreased in solution $\mathrm{pH} 7.0-10.0$ and 4.0-2.0. The presence of electrolytes such as $\mathrm{NaCl}$ in aqueous solution had a significant negative effect on the adsorption. The mechanisms controlling the adsorption were supposed to be chemisorption.
\end{abstract}

\section{Introduction}

Since tetracycline antibiotics (TCs) came into existence, they have been widely used in the treatment of various bacteria and rickettsia, chlamydia, mycoplasma, and so forth, which are considered as broad-spectrum antibiotics for human beings. Clinical research shows that TCs can directly enter the fetus through placental barrier and cause color change of teeth, badly regrown of enamel, and restraining the growth of bones [1,2]. After the availability of other more effective medicines, TCs have been rarely used in human being. However, because they can act effectively against a wide range of disease-causing bacteria and have low price, TCs swiftly spread in livestock industry $[3,4]$. According to preliminary statistics, the output of TCs is $9.7 \times 10^{4} \mathrm{t}$ per year in China, more than $70 \%$ of which are used in the livestock industry [5]. Some research show that after animals are fed with TCs, about $25-75 \%$ [6] even $70-90 \%[7,8]$ of the dose cannot be used by the animal bodies. Thus, it directly comes into the environment as its primary form or metabolin through urine or excrement, as a result, bringing potential risks to the environmental quality. Oxytetracycline (OTC) is the sort of the earliest and the most widely used TCs. The amount used in the livestock industry makes people astonished. Furthermore, it is drained easily through urine out of bodies [9]. Nowadays residual OTC has been already detected from soils [10], rivers [11], and sediments [12], and so forth, in many countries and areas. Furthermore, OTC is hard to be degraded by organisms in the environment [13]. Therefore, the environmental risks caused by OTC become very concerned by the society.

In recent years, research on the environmental impacts from OTC mainly focused on environmental survey and the analysis of adsorption behaviors in soils. The factors such as soil types [14], organic matter content [15], particle size [16], aluminum and iron hydrous oxides [3], cation species [17], play an important role in adsorption of OTC in soils. The removal of OTC mainly depends on its sorption on the sewage sludge and its degradation or transformation during the treatment. The sorption efficiency of OTC may be 


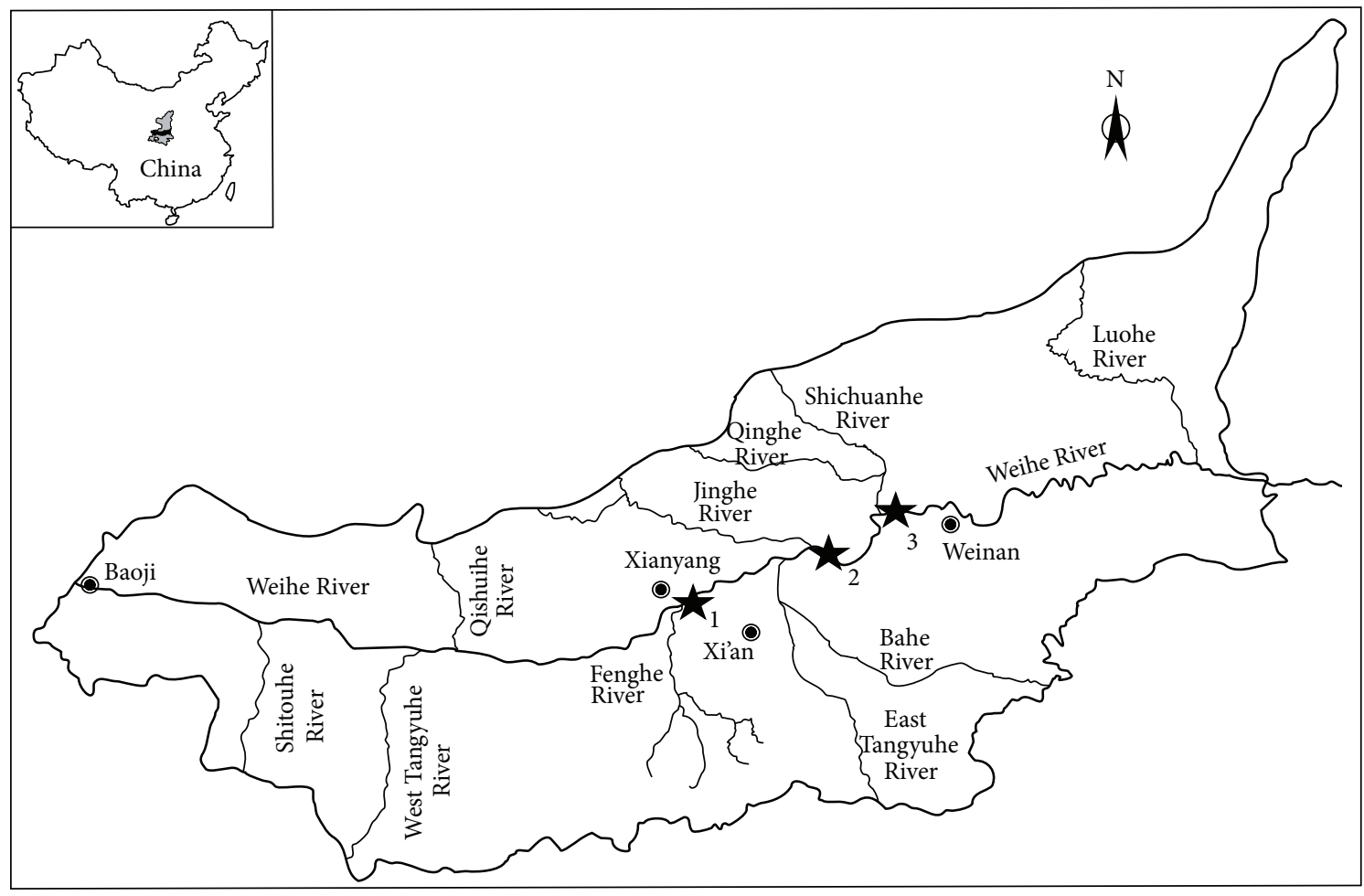

C City
Sampling point

FIGURE 1: The sampling points of sediment in different locations.

significantly altered by the initial concentration, the $\mathrm{pH}$, the temperature, and the presence of other species in the solution $[18,19]$.

When polluted surface water (mainly river water) infiltrates to the subsurface system, river sediment is the important medium which influences the water movement and solute transport to the groundwater system. The adsorption characteristics of pollutants onto river sediment directly influence their mobility from the sediment-water interface to sediments beneath the channel surface. In a certain time, sediment is to adsorb and detain pollutants in sediment layers so that water can move through, preventing the groundwater from pollution $[20,21]$. The persistence of this function is directly relevant to the adsorption characteristics of pollutants onto sediment. However, researchers have reported the adsorption characteristics of polycyclic aromatic hydrocarbon [22], organochlorine pesticides [23], florfenicol [24], and so forth, onto different sediments while the adsorption behaviors of OTC onto the sediments in the Weihe River are rarely reported. The Weihe River is the biggest tributary of the Yellow River, and a large population resides in the Weihe River basin. Many cities and livestock industries lie along it. A large quantity of OTC enters the Weihe River through sewage system of municipal works. The previous survey along the Weihe River basin by the authors shows that there has been detected residue of OTC in the water, and the concentration level reaches the degree of $\mathrm{ng} / \mathrm{L} \sim \mu \mathrm{g} / \mathrm{L}$ with great seasonal variations. Therefore, research on adsorption behaviors of OTC onto sediment in the Weihe River is important to understand the occurrence and tendency of OTC in the Weihe River basin. Such research also provides the theoretical basis for the effective prevention of OTC pollution to the groundwater system in the Weihe River basin.

This study collected sediment samples from several tributaries in the mid-Weihe River for systematical analysis of the impact factors in the processes of OTC adsorption onto the sediments. These factors include contact time, solution $\mathrm{pH}$, temperature, and ionic strength. The experimental results were analyzed by kinetic and isotherm models. Thermodynamics parameters such as Gibbs-free energy change $\left(\Delta G^{\circ}\right)$, enthalpy change $\left(\Delta H^{\circ}\right)$, and entropy change $\left(\Delta S^{\circ}\right)$ were calculated. The mechanisms for OTC adsorption onto the sediment of the Weihe River were also examined.

\section{Experimental}

2.1. Sediment Samples. One sediment sample was collected from the confluence of the Fenghe River, the Bahe River, and the Shichuanhe River with the Weihe River, respectively. Thus, our experiments used a total of three sediment samples. The sampling points of sediment in different locations are shown in Figure 1. The sediment samples were not polluted by OTC, and they were air-dried and sterilized for the lab 
TABle 1: Physicochemical property of the sediment samples.

\begin{tabular}{|c|c|c|c|c|c|c|c|c|c|}
\hline \multirow{2}{*}{$\begin{array}{l}\text { Sampling } \\
\text { point }\end{array}$} & \multirow{2}{*}{$\begin{array}{c}\text { Organic } \\
\text { carbon } \\
\text { (weight\%) }\end{array}$} & \multirow{2}{*}{$\begin{array}{c}\text { Moisture } \\
\text { content } \\
\text { (weight\%) }\end{array}$} & \multirow{2}{*}{$\begin{array}{l}\text { Volume } \\
\text { weight } \\
\left(\mathrm{g} / \mathrm{cm}^{3}\right)\end{array}$} & \multirow[b]{2}{*}{$\begin{array}{c}\text { Porosity } \\
\text { (\%) }\end{array}$} & \multirow[b]{2}{*}{$\mathrm{pH}_{\mathrm{ZPC}}$} & \multicolumn{4}{|c|}{ Mechanical composition (weight\%) } \\
\hline & & & & & & $\begin{array}{c}\text { Silt } \\
<0.25 \mathrm{~mm}\end{array}$ & $\begin{array}{c}\text { Fine sand } \\
0.25-0.35 \mathrm{~mm}\end{array}$ & $\begin{array}{c}\text { Medium sand } \\
0.35-0.5 \mathrm{~mm}\end{array}$ & $\begin{array}{c}\text { Coarse sand } \\
>0.5 \mathrm{~mm}\end{array}$ \\
\hline 1 & 0.33 & 5.84 & 1.54 & 41.81 & 5.86 & 1.52 & 48.50 & 39.82 & 10.16 \\
\hline 2 & 0.46 & 5.90 & 1.53 & 42.42 & 5.63 & 1.85 & 52.20 & 41.03 & 4.92 \\
\hline 3 & 0.59 & 6.34 & 1.52 & 42.68 & 5.57 & 2.73 & 56.62 & 37.80 & 2.85 \\
\hline
\end{tabular}

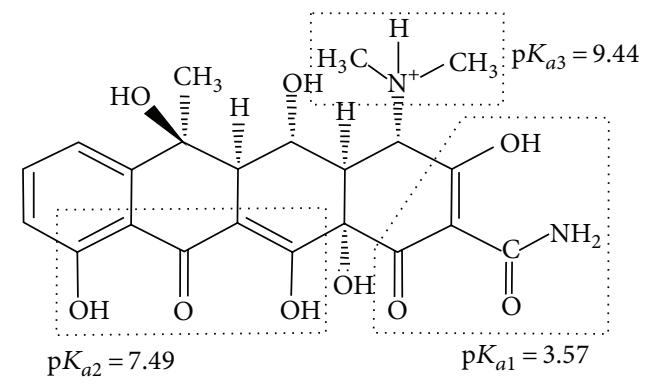

FIGURE 2: Molecular structure and $\mathrm{p} K_{a}$ values of OTC [25].

analysis. Some basic physicochemical properties of the sediments are listed in Table 1.

2.2. Chemical Reagent. OTC was purchased from Boston Biomedical Inc., (USA) with United States Patent (USP) grade. OTC's molecular formula is $\mathrm{C}_{22} \mathrm{H}_{24} \mathrm{~N}_{2} \mathrm{O}_{9}$, and its molecular weight is 460.44. Molecular structure and $\mathrm{p} K_{a}$ values of OTC were shown in Figure 2. Methylalcohol in flowing phase was purchased from Waters Company (USA) with High Performance Liquid Chromatography (HPLC) grade. The other reagents are all in analytical grade.

2.3. Detection Method of OTC in Solution. A Waters ACQUITY Ultra Performance Liquid Chromatography (UPLC) H-Class with ultraviolet/visible spectrophotometry detector and BEH Shield RP18 $1.7 \mu \mathrm{m} 2.1 \times 150 \mathrm{~mm}$ column was used for the quantification of OTC in solution, under the optimized conditions as follows: methanol/water $=50: 50$ as mobile phase, $0.2 \mathrm{~mL} / \mathrm{min}$ of flow rate, $20^{\circ} \mathrm{C} \pm 0.1^{\circ} \mathrm{C}$ column temperature, $5 \mu \mathrm{L}$ of injection volume, $260 \mathrm{~nm}$ detected wavelength, and $2.610 \mathrm{~min}$ of retention time.

2.4. Adsorption Procedure. Adsorption experiments were conducted by Organization for Economic Co-operation and Development (OECD) batch equilibrium method [26]. For each time $0.2000 \mathrm{~g}$ sediments and $1 \mathrm{~mL}$ OTC solution were mixed in a $5 \mathrm{~mL}$ centrifuge tube, which was then shaken in a thermostat shaker at $150 \mathrm{rpm}$.

2.5. Adsorption Kinetics. The kinetic studies were performed following a similar procedure at $25^{\circ} \mathrm{C}(298 \mathrm{~K}, \mathrm{pH} 7.0)$, the initial concentration was set as $2.00 \mathrm{mg} / \mathrm{L}$ for each OTC in a series of reactors with the same specification, and the aqueous samples were separated at predetermined time intervals by using filter membranes of $0.22 \mu \mathrm{m}$. The concentrations of OTC were analyzed by UPLC. Each experiment was duplicated under identical conditions and for each time interval two replicate samples were available. Blanks containing no OTC were done and the loss (generally quite low) was considered. The uptake of OTC at time $t, Q_{t}(\mathrm{mg} / \mathrm{kg})$, was calculated by the following equation:

$$
Q_{t}=\frac{V\left(C_{0}-C_{t}\right)}{m}
$$

where $C_{0}$ and $C_{t}$ are the initial and $t$ time's concentrations of the OTC $(\mathrm{mg} / \mathrm{L})$ in the solution, respectively, $V$ is the volume of the solution (L), and $m$ is the weight of the sediment samples $(\mathrm{g})$.

2.6. Adsorption Isotherm. In adsorption isotherm studies, solutions with different initial concentrations were added, which ranged from 0.2 to $10 \mathrm{mg} / \mathrm{L}(0.2,0.5,1.0,2.0,5.0$, and $10 \mathrm{mg} / \mathrm{L}, \mathrm{pH} 7.0$ ), and the equilibrium time was set as $24 \mathrm{~h}$, which was long enough according to the kinetic studies. The aqueous samples were separated by using filter membranes of $0.22 \mu \mathrm{m}$. The concentrations of OTC were analyzed by UPLC. Each initial concentration had two replicate samples. Blanks containing no OTC were done and the loss (generally quite low) was considered. The uptake of OTC at equilibrium, $Q_{e}$ $(\mathrm{mg} / \mathrm{L})$, was calculated by the following equation:

$$
Q_{e}=\frac{V\left(C_{0}-C_{e}\right)}{m}
$$

where $C_{e}$ is the equilibrium concentration of the OTC $(\mathrm{mg} / \mathrm{L})$ in the solution.

2.7. Thermodynamics. In thermodynamics study, the initial concentration ranged from 0.2 to $10.0 \mathrm{mg} / \mathrm{L}(0.2,0.5,1.0,2.0$, 5.0 , and $10.0 \mathrm{mg} / \mathrm{L}, \mathrm{pH} 7.0)$ at $25^{\circ} \mathrm{C}(298 \mathrm{~K}), 30^{\circ} \mathrm{C}(308 \mathrm{~K})$, and $35^{\circ} \mathrm{C}(318 \mathrm{~K})$. After $24 \mathrm{~h}$, the aqueous samples were separated by using filter membranes of $0.22 \mu \mathrm{m}$. The concentrations of OTC were analyzed by UPLC. Blanks containing no OTC were done and the loss (generally quite low) was considered.

2.8. Effect of Solution $p H$. The effect of solution $\mathrm{pH}$ on OTC adsorption was investigated by adjusting OTC solutions (the initial concentration was $2 \mathrm{mg} / \mathrm{L}$ ) to different initial $\mathrm{pH}$ values $(2.0,3.0,4.0,5.0,6.0,7.0,8.0,9.0,10.0)(0.1 \mathrm{~mol} / \mathrm{L} \mathrm{NaCl}$ was used to make sure each sample had the same volume after adjusting the initial $\mathrm{pH}$ by $0.1 \mathrm{~mol} / \mathrm{L} \mathrm{HCl}$ and $\mathrm{NaOH}$. Due to the $\mathrm{NaCl}, \mathrm{NaOH}$ and $\mathrm{HCl}$ had the same concentration 


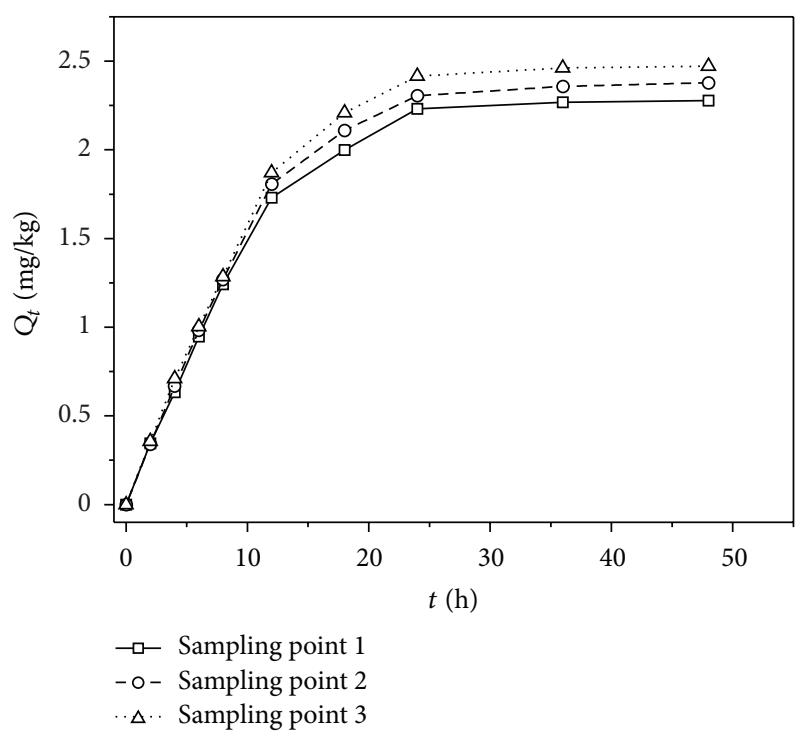

Figure 3: Effect of contact time on OTC adsorption onto sediment samples.

and valence state after ionization, thus each sample had the same ion strength) at $25^{\circ} \mathrm{C}(298 \mathrm{~K})$. After $24 \mathrm{~h}$, the aqueous samples were separated by using filter membranes of $0.22 \mu \mathrm{m}$. The concentrations of OTC were analyzed by UPLC. Blanks containing no sediment samples were done.

2.9. Effect of Ionic Strength. The effect of ionic strength on OTC adsorption was investigated by adjusting OTC solutions (the initial concentration was $2 \mathrm{mg} / \mathrm{L}, \mathrm{pH} 7.0$ ) to different concentrations of $\mathrm{NaCl}(0.17,0.34,0.86,1.71,3.42,8.56$, $17.11 \mathrm{mmol} / \mathrm{L})$ at $25^{\circ} \mathrm{C}(298 \mathrm{~K})$. After $24 \mathrm{~h}$, the aqueous samples were separated by using filter membranes of $0.22 \mu \mathrm{m}$. The concentrations of OTC were analyzed by UPLC. Blanks containing no $\mathrm{NaCl}$ were done.

\section{Results and Discussion}

3.1. Adsorption Kinetics. The adsorption of OTC onto sediment samples as a function of contact time at solution $\mathrm{pH}$ 7.0 is shown in Figure 3. Results showed that the rate of adsorption was rapid at the first 12 hours and gradually decreased with increasing contact time until equilibrium was attained, which was considered at 24 hours. It was possible that at the beginning of adsorption, there existed enough sorption sites on the surface of sediment samples which was beneficial to adsorption of OTC. Furthermore, the initial concentration of OTC provided the necessary driving force to overcome the resistances of mass transfer between the aqueous phases and the solid phase. With increasing contact time, sorption sites on the surface of sediment samples were close to saturation which made adsorption of OTC transfer from the surface into void of sediment samples. Due to the increase of the resistance function, the rate of adsorption was gradually decreased until equilibrium was attained [27].

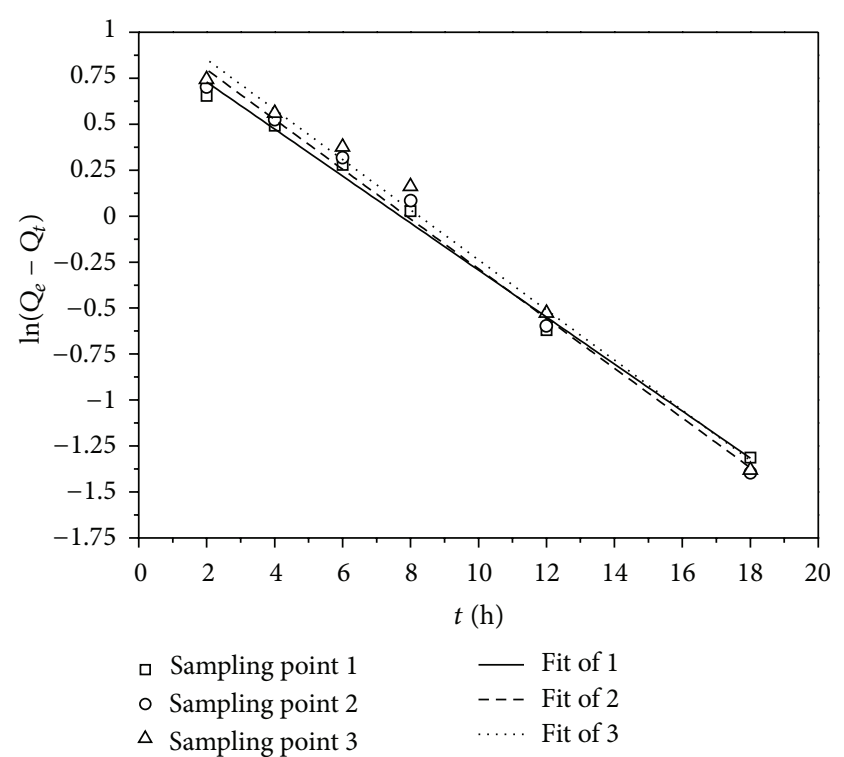

FIGURE 4: Simulated results of pseudo-first-order kinetics.

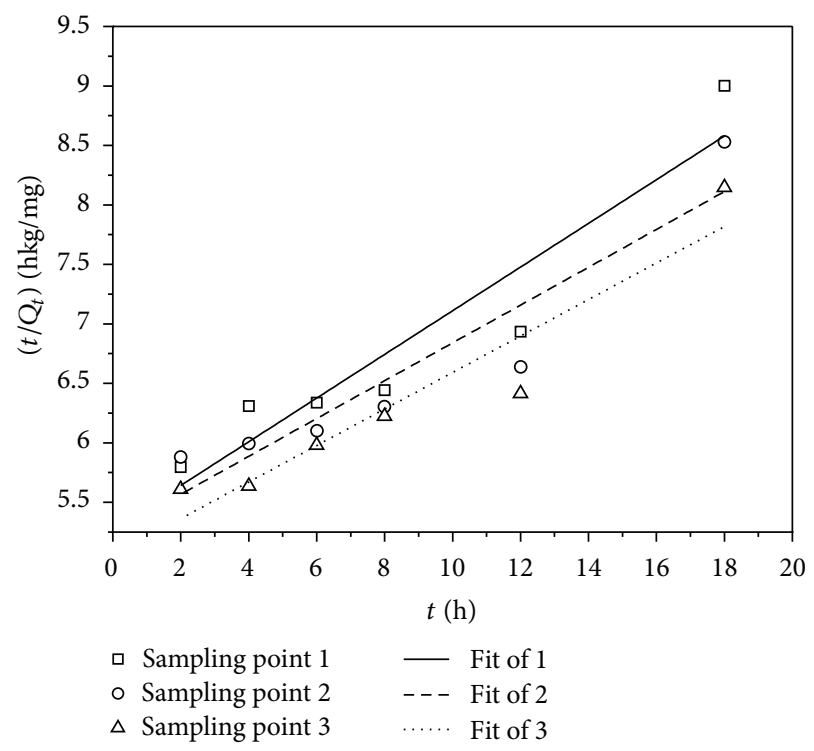

FIGURE 5: Simulated results of pseudo-second-order kinetics.

Two widely used kinetic models, pseudo-first-order and pseudo-second-order kinetic models, were employed to interpret the kinetics results. The linearized form of pseudofirst-order kinetic model is given as follows $[28,29]$ :

$$
\ln \left(Q_{e}-Q_{t}\right)=\ln Q_{e}-k_{1} t,
$$

where $Q_{e}(\mathrm{mg} / \mathrm{kg})$ and $Q_{t}(\mathrm{mg} / \mathrm{kg})$ are the OTC adsorption capacities for sediment samples at the equilibrium and at any time $t(\mathrm{~h})$, respectively. $k_{1}(1 / \mathrm{h})$ is the rate constant of pseudofirst-order kinetic model. The linear plot (Figure 4$)$ of $\ln \left(Q_{e}-\right.$ $\left.Q_{t}\right)$ versus $t$ was used to calculate the rate constant $k_{1}$, the equilibrium adsorption capacity $Q_{e}$, and the determination coefficient $R^{2}$, and the results are given in Table 2 . 
TABLE 2: Pseudo-first-order and pseudo-second-order rate constants for OTC adsorption onto sediment samples.

\begin{tabular}{lccccccc}
\hline \multirow{2}{*}{ Sampling point } & \multirow{2}{*}{$Q_{e, \text { exp }}(\mathrm{mg} / \mathrm{kg})$} & \multicolumn{3}{c}{ Pseudo-first-order model } & \multicolumn{3}{c}{ Pseudo-second-order model } \\
& & $R^{2}$ & $k_{1}(1 / \mathrm{h})$ & $Q_{e, \mathrm{cal}}(\mathrm{mg} / \mathrm{kg})$ & $R^{2}$ & $k_{2}(\mathrm{~kg} / \mathrm{mg} \cdot \mathrm{h})$ & $Q_{e, \mathrm{cal}}(\mathrm{mg} / \mathrm{kg})$ \\
\hline 1 & 2.2685 & 0.9916 & 0.1278 & 2.6773 & 0.8684 & 0.0064 \\
2 & 2.3577 & 0.9900 & 0.1353 & 2.9058 & 0.8452 & 0.0048 \\
3 & 2.4610 & 0.9860 & 0.1363 & 3.0801 & 0.8857 & 0.0046 & 6.2909 \\
\hline
\end{tabular}

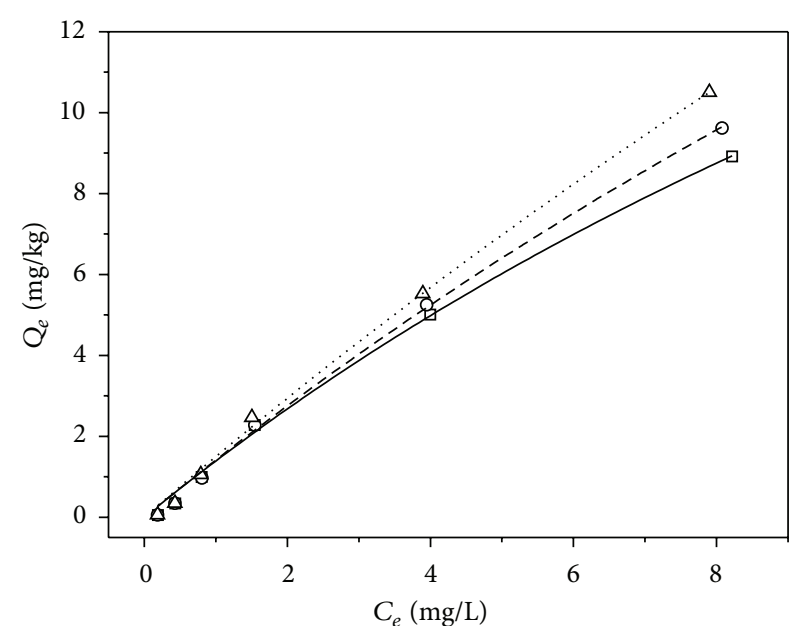

口 Sampling point 1

- Sampling point 2

$\triangle$ Sampling point 3

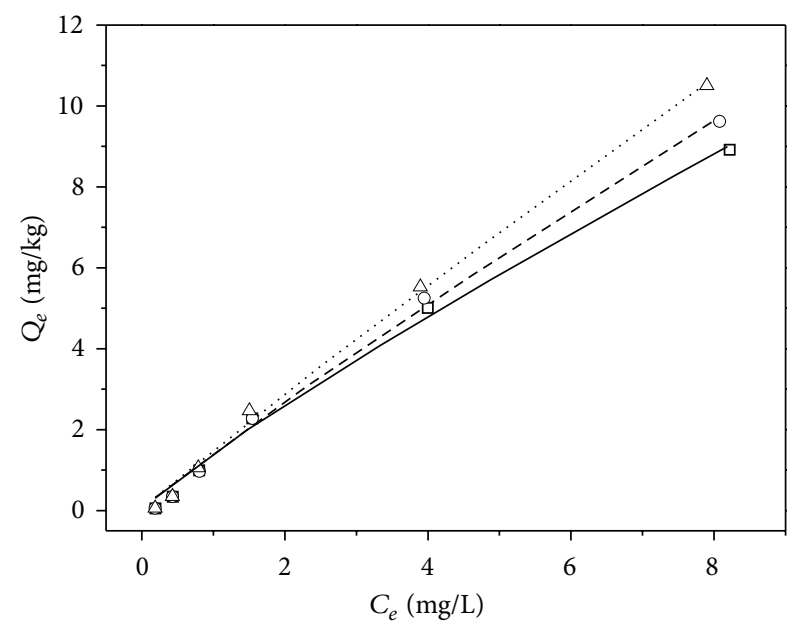

口 Sampling point 1 - Freundlich fit of 1

- Sampling point $2 \quad$ - - Freundlich fit of 2

$\Delta$ Sampling point $3 \quad \ldots$. . Freundlich fit of 3

(b)

FIGURE 6: Two-parameter isotherm models (Langmuir and Freundlich) fit of adsorption isotherm.

The linearized form of pseudo-second-order kinetic model is given as follows $[28,29]$ :

$$
\frac{t}{Q_{t}}=\frac{1}{k_{2} Q_{e}^{2}}+\frac{t}{Q_{e}}
$$

where $k_{2}(\mathrm{~kg} / \mathrm{mg} \cdot \mathrm{h})$ is the rate constant of pseudo-secondorder kinetic model. The values of equilibrium adsorption capacity $Q_{e}$ and rate constant $k_{2}$, calculated from the intercept and the slope (Figure 5) of the linear plot of $t / Q_{t}$ versus $t$, along with the value of determination coefficient $R^{2}$, are listed in Table 2.

The $R^{2}$ values obtained by the pseudo-first-order kinetic model were very high, and the calculated $Q_{e}$ values were in good agreement with the experimental results, suggesting the applicability of the pseudo-first-order kinetic model to describe the adsorption kinetics data of OTC onto the sediment samples.

3.2. Adsorption Isotherm. The adsorption isotherms of OTC onto sediment samples were studied at $25^{\circ} \mathrm{C}(298 \mathrm{~K})$ and solution $\mathrm{pH}$ 7.0. Results showed that the OTC adsorption capacity increased with increasing the equilibrium OTC concentration. Two-parameter isotherm models (Langmuir and Freundlich) were used to fit the experimental data which are shown in Figure 6.
The linearized form of Langmuir isotherm model can be written as [30]

$$
\frac{C_{e}}{Q_{e}}=\frac{1}{Q_{\max } K_{L}}+\frac{C_{e}}{Q_{\max }},
$$

where $C_{e}(\mathrm{mg} / \mathrm{L})$ is the equilibrium concentration of OTC in solution. $Q_{e}(\mathrm{mg} / \mathrm{kg})$ is the OTC adsorption capacity onto sediment samples. $Q_{\max }(\mathrm{mg} / \mathrm{kg})$ is the maximum OTC adsorption capacity onto sediment samples. $K_{L}(\mathrm{~L} / \mathrm{mg})$ is the Langmuir isotherm constant related to the free energy of adsorption. The values of $Q_{\max }$ and $K_{L}$ can be calculated from the intercept and the slope of the straight line of the linearized form of the Langmuir isotherm.

The linearized form of Freundlich isotherm model can be written as [30]

$$
\ln Q_{e}=\ln K_{F}+\frac{1}{n} \ln C_{e},
$$

where $K_{F}\left((\mathrm{mg} / \mathrm{kg})(\mathrm{L} / \mathrm{mg})^{1 / n}\right)$ and $1 / n$ are the Freundlich constants which are related to the adsorption capacity and adsorption intensity, respectively. The values of $K_{F}$ and $1 / n$ can be calculated from the intercept and the slope of the straight line of the linearized form of the Freundlich isotherm. 
TABLE 3: Isotherm parameters for OTC adsorption onto sediment samples.

\begin{tabular}{lccccrr}
\hline \multirow{2}{*}{ Sampling point } & \multicolumn{3}{c}{ Langmuir isotherm } & \multicolumn{3}{c}{ Freundlich isotherm } \\
& $Q_{m}(\mathrm{mg} / \mathrm{kg})$ & $K_{L}(\mathrm{~L} / \mathrm{mg})$ & $R^{2}$ & $R_{L}$ & $K_{F}\left((\mathrm{mg} / \mathrm{kg})(\mathrm{L} / \mathrm{mg})^{1 / n}\right)$ & $1 / n$ \\
\hline 1 & 35.9319 & 0.0403 & 0.9965 & 0.9007 & 1.4154 & 0.8795 \\
2 & 54.6655 & 0.0266 & 0.9970 & 0.9297 & 1.4202 & 0.9934 \\
3 & 81.8869 & 0.0187 & 0.9967 & 0.9484 & 1.5054 & 0.9211 \\
\hline
\end{tabular}

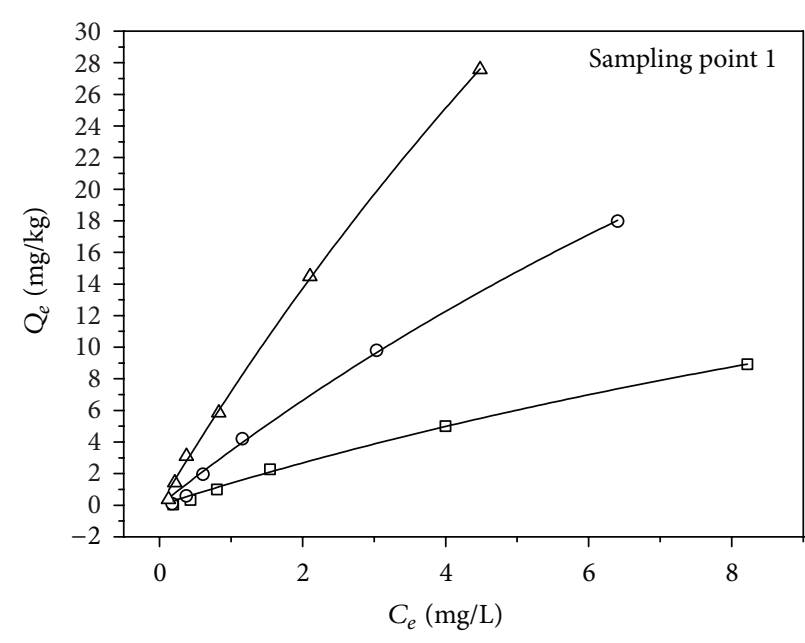

(a)

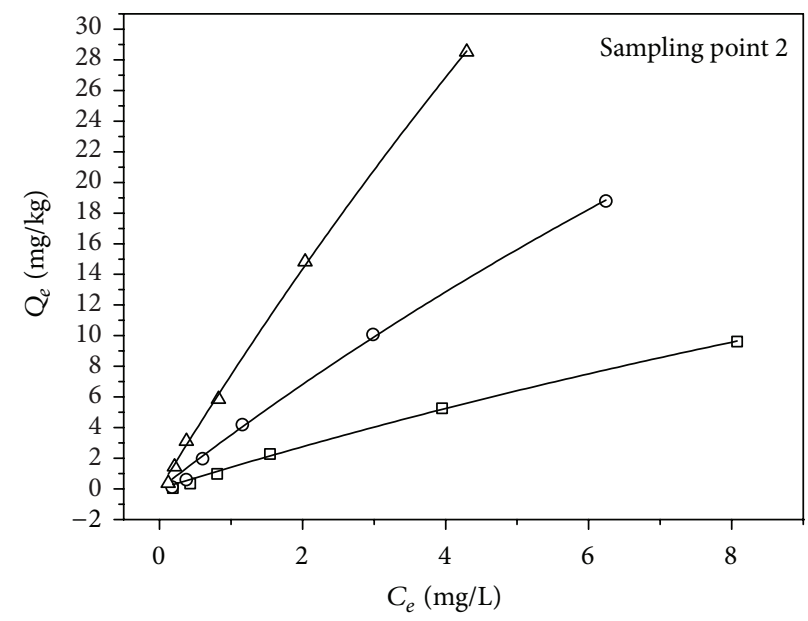

(b)

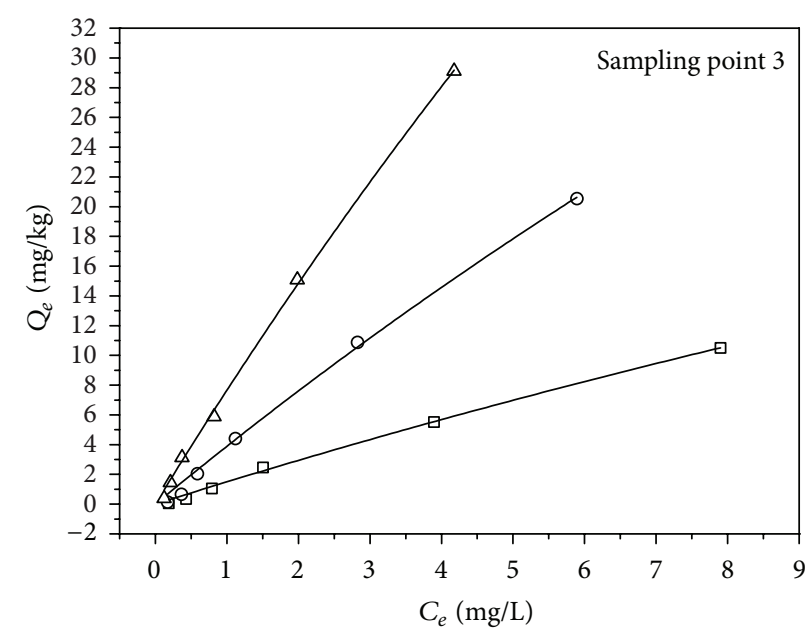

ㅁ $298 \mathrm{~K}$

- $308 \mathrm{~K}$

$\triangle 318 \mathrm{~K}$

(c)

FIGURE 7: Langmuir fit of OTC adsorption onto sediment samples in different temperatures.

The parameters of Langmuir and Freundlich isotherm models for OTC adsorption on to sediment samples, along with the values of determination coefficient $\left(R^{2}\right)$ are given in Table 3.

The values of $R^{2}$ for Langmuir and Freundlich isotherm models were both high, and the values of $R^{2}$ for Langmuir isotherm model was a little higher. Generally speaking, the value of $R^{2}$ is widely used to investigate the applicability of a model in fitting to data. However, it cannot be the only standard due to the inherent deviation of linear regression. For the purpose of quantitatively comparing the applicability of Langmuir and Freundlich adsorption isotherms in fitting to data, the following four error functions were employed for error analysis [31].

The sum of the squares of the errors (SSE):

$$
\mathrm{SSE}=\sum_{i=1}^{n}\left(Q_{e, \mathrm{cal}}-Q_{e, \exp }\right)_{i}^{2} .
$$


TABLE 4: Isotherm simulated results with error analysis for OTC adsorption onto sediment samples.

\begin{tabular}{|c|c|c|c|c|c|c|c|c|}
\hline \multirow{2}{*}{ Sampling point } & \multicolumn{4}{|c|}{ Langmuir isotherm } & \multicolumn{4}{|c|}{ Freundlich isotherm } \\
\hline & SSE & SAE & HYBRID & NPSD (\%) & SSE & SAE & HYBRID & NPSD (\%) \\
\hline 1 & 0.1662 & 0.8229 & 18.3845 & 180.1580 & 0.3114 & 1.2962 & 35.5362 & 226.2888 \\
\hline 2 & 0.1673 & 0.8697 & 17.3086 & 169.1859 & 0.2737 & 1.2220 & 28.0189 & 195.2054 \\
\hline 3 & 0.2136 & 0.9115 & 19.2294 & 173.3438 & 0.2731 & 1.1488 & 28.5811 & 192.4854 \\
\hline
\end{tabular}

The sum of the absolute errors (SAE):

$$
\mathrm{SAE}=\sum_{i=1}^{n}\left|Q_{e, \mathrm{cal}}-Q_{e, \exp }\right|_{i} .
$$

The hybrid fractional error function (HYBRID):

$$
\text { HYBRID }=\frac{100}{n-p} \sum_{i=1}^{n}\left[\frac{\left(Q_{e, \text { cal }}-Q_{e, \exp }\right)^{2}}{Q_{e, \exp }}\right]_{i} .
$$

Normalized percentage standard deviation (NPSD):

$$
\operatorname{NPSD}(\%)=100 \sqrt{\frac{1}{n-1} \sum_{i=1}^{n}\left(\frac{Q_{e, \mathrm{cal}}-Q_{e, \exp }}{Q_{e, \exp }}\right)_{i}^{2}},
$$

where $Q_{e, \text { exp }}$ and $Q_{e, \text { cal }}$ are, respectively, the experimental values and calculated values by the adsorption isotherm and $n$ and $p$ refer to the number of data points and the number of isotherm parameter, respectively.

The error analysis results for OTC adsorption onto sediment samples of Langmuir and Freundlich isotherm models in this study are shown in Table 4.

By inspecting Table 4 , it further proved that the Langmuir isotherm was more suitable to describe the adsorption behavior of OTC onto sediment samples as it gave a comparatively lower error function compared with the Freundlich model. The essential characteristics of the Langmuir isotherm can be expressed in terms of a dimensionless constant separation factor, $R_{L}$, which is defined as follows [30]:

$$
R_{L}=\frac{1}{1+K_{L} C_{0}}
$$

where $C_{0}(\mathrm{mg} / \mathrm{L})$ is the initial concentration of OTC in solution. The adsorption is considered favorable when $0<$ $R_{L}<1$ and linear when $R_{L}=1$ [32]. The values of $R_{L}$ obtained in this study were between 0.9007 and 0.9484 (Table 3 ) which were close to 1 , indicating that the adsorption of OTC onto sediment samples was favorable. The Langmuir isotherm model presents linearity at low equilibrium concentration which is fitting to the data.

3.3. Thermodynamics. The adsorption of OTC onto sediment samples were studied as a function of temperature $(298 \mathrm{~K}$, $308 \mathrm{~K}, 318 \mathrm{~K}$ ) at solution $\mathrm{pH}$ 7.0. The above experimental data were evaluated by Langmuir isotherm model (Figure 7) as it is more suitable to describe the adsorption behavior of OTC onto sediment samples. The obtained results are listed in Table 5. The values of $K_{L}$ for the Langmuir isotherm at $298 \mathrm{~K}$,
TABLE 5: Langmuir isotherm parameters for OTC adsorption onto sediment samples at different temperatures.

\begin{tabular}{lcccc}
\hline $\begin{array}{l}\text { Sampling } \\
\text { point }\end{array}$ & & \multicolumn{3}{c}{ Temperature } \\
\hline \multirow{4}{*}{1} & $Q_{m}(\mathrm{mg} / \mathrm{kg})$ & 35.9319 & 82.2209 & 150.3823 \\
& $K_{L}(\mathrm{~L} / \mathrm{mg})$ & 0.0403 & 0.0439 & 0.0502 \\
& $K_{L}(\mathrm{~L} / \mathrm{mol})$ & 18537.3144 & 20190.2940 & 23091.0660 \\
& $R^{2}$ & 0.9965 & 0.9953 & 0.9988 \\
\hline \multirow{4}{*}{2} & $Q_{m}(\mathrm{mg} / \mathrm{kg})$ & 54.6653 & 112.3406 & 210.6777 \\
& $K_{L}(\mathrm{~L} / \mathrm{mg})$ & 0.0266 & 0.0323 & 0.0365 \\
& $K_{L}(\mathrm{~L} / \mathrm{mol})$ & 12224.6820 & 14872.2120 & 16819.8732 \\
& $R^{2}$ & 0.9970 & 0.9987 & 0.9987 \\
\hline \multirow{4}{*}{3} & $Q_{m}(\mathrm{mg} / \mathrm{kg})$ & 81.8869 & 171.3534 & 253.6336 \\
& $K_{L}(\mathrm{~L} / \mathrm{mg})$ & 0.0187 & 0.0232 & 0.0311 \\
& $K_{L}(\mathrm{~L} / \mathrm{mol})$ & 8587.206 & 10700.6256 & 14324.2884 \\
& $R^{2}$ & 0.9967 & 0.9952 & 0.9985 \\
\hline
\end{tabular}

$308 \mathrm{~K}$, and $318 \mathrm{~K}$ were used to calculate thermodynamic parameters such as Gibbs-free energy change $\left(\Delta G^{\circ}\right)$, enthalpy change $\left(\Delta H^{\circ}\right)$, and entropy change $\left(\Delta S^{\circ}\right)$ using the following equations [30, 33]:

$$
\begin{aligned}
\Delta G^{\circ} & =-R T \ln K_{L}, \\
\ln K_{L} & =\frac{\Delta S^{\circ}}{R}-\frac{\Delta H^{\circ}}{R T},
\end{aligned}
$$

where $K_{L}(\mathrm{~L} / \mathrm{mol})$ is the Langmuir constant. $R(8.314 \mathrm{~J} / \mathrm{mol} \cdot \mathrm{K})$ is the gas constant. $T(\mathrm{~K})$ is the absolute temperature. The values of $\Delta H^{\circ}$ and $\Delta S^{\circ}$ can be calculated from the intercept and the slope of the linear plot of $\ln K_{L}$ versus $1 / T$. The obtained values of thermodynamic parameters for OTC adsorption onto sediment samples are given in Table 6.

Results showed that the OTC adsorption capacity for sediment samples increased with increasing temperature, which indicated that the adsorption of OTC onto sediment samples was favored at higher temperature. The negative values of $\Delta G^{\circ}$ suggest the feasibility of the adsorption of OTC onto sediment samples and the spontaneous nature of the adsorption process [34]. The positive values of $\Delta H^{\circ}$ indicate that the adsorption process is endothermic in nature [35]. The positive values of $\Delta S^{\circ}$ show an increase in randomness at the solid/liquid interface during the adsorption process [36].

3.4. Effect of Solution $p H$. Solution $\mathrm{pH}$ usually influences the adsorption to a large extent, as it affects the properties of both adsorbent and adsorbate. Furthermore, the $\mathrm{pH}$ of the 
TABLE 6: Thermodynamic parameters for OTC adsorption onto sediment samples.

\begin{tabular}{lcccrrr}
\hline Sampling point & \multirow{2}{*}{$\Delta H^{\circ}(\mathrm{kJ} / \mathrm{mol})$} & $\Delta S^{\circ} /(\mathrm{kJ} / \mathrm{mol} \cdot \mathrm{K})$ & \multicolumn{2}{c}{$\Delta G^{\circ}(\mathrm{kJ} / \mathrm{mol})$} & \multicolumn{2}{c}{$318 \mathrm{~K}$} \\
\hline 1 & 8.6293 & 0.1106 & -24.3484 & -25.3842 & -26.5633 \\
2 & 12.5973 & 0.1206 & -23.3170 & -24.6014 & -25.7255 \\
3 & 20.1193 & 0.1427 & -22.4419 & -23.7584 & -25.3009 & 0.9575 \\
\hline
\end{tabular}

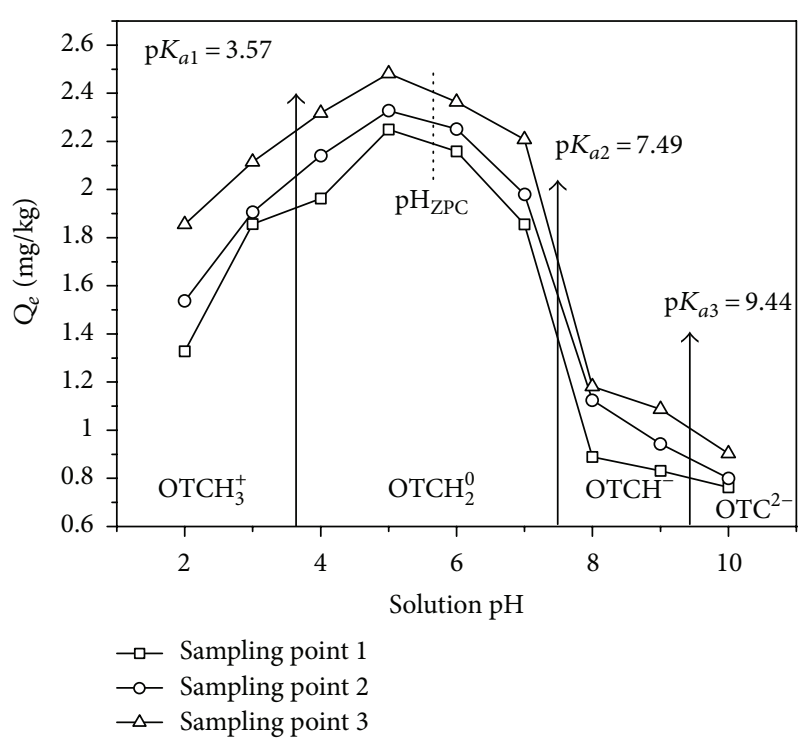

FIGURE 8: Effect of solution pH on OTC adsorption onto sediment samples as well as OTC existence forms in different $\mathrm{pH}$ conditions.

solution affects the degree of ionization and the speciation of tetracycline hydrochloride which subsequently leads to a change in adsorption kinetics and equilibrium characteristics [37]. The effect of solution $\mathrm{pH}$ on OTC adsorption onto sediment samples as well as OTC existence forms in different conditions is shown in Figure 8. It was observed that the adsorption capacity of OTC onto sediment samples from solution $\mathrm{pH} 4.0$ to 7.0 did not cause obvious change. However, from solution $\mathrm{pH} 2.0$ to 4.0 and 7.0 to 9.0 , the adsorption capacity both decreased, and it decreased more sharply from solution $\mathrm{pH} 7.0$ to 9.0. After solution $\mathrm{pH}$ reached 9.0, the adsorption capacity decreased lightly. The surface charge property of soil and sediment is related to its $\mathrm{pH}$ of zero point charge $\left(\mathrm{pH}_{\mathrm{ZPC}}\right)$. When the environmental $\mathrm{pH}<\mathrm{pH}_{\mathrm{ZPC}}$, the surface of soil and sediment is positively charged while the environmental $\mathrm{pH}>\mathrm{pH}_{\mathrm{ZPC}}$, the surface of soil and sediment is negatively charged [38, 39]. Chang et al. had already reported that tetracycline exist forms in different $\mathrm{pH}$ [40]. While solution $\mathrm{pH} \leq 3.0$, OTC is in its cationic form of $\mathrm{OTCH}^{3+}$ and it may help decreasing electrostatic attractions between the sediments surface and itself. Moreover, in such a low $\mathrm{pH}$, the competition between hydronium and $\mathrm{OTCH}^{3+}$ for sorption sites could partially offset the uptake of OTC. At solution $\mathrm{pH}$ 4.0-7.0, the OTC is in its zwitterionic form $\mathrm{OTCH}_{2}{ }^{0}$. It is controversial that the higher uptake of OTC in its zwitterionic form at solution $\mathrm{pH} 4.0-7.0$ could be

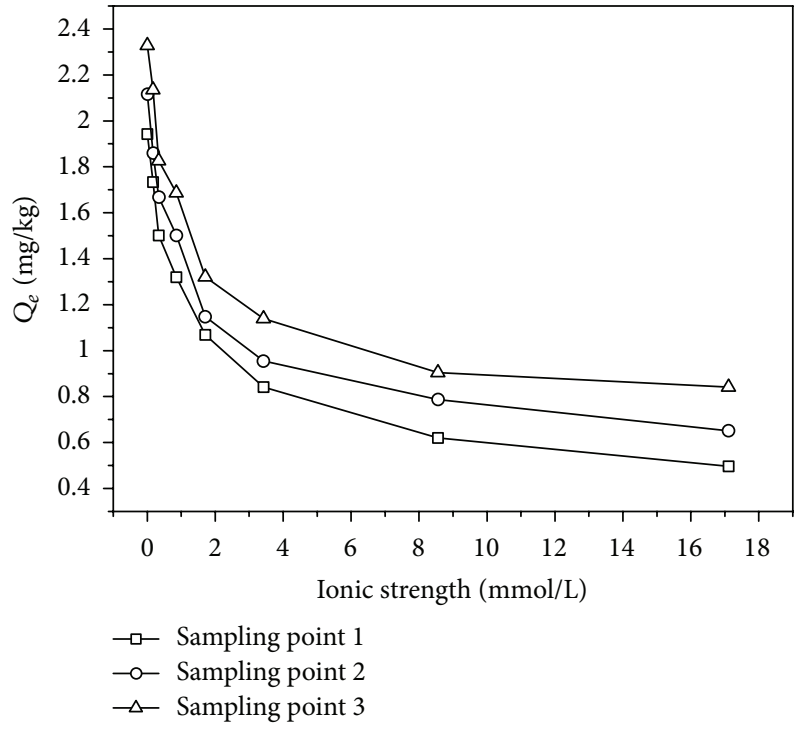

FIGURE 9: Effect of ionic strength on OTC adsorption onto sediment samples.

dominated by other interactions such as complexation [40]. While solution $\mathrm{pH}>7.0$, OTC is negatively charged which resulted in increasing repulsion with the sediment surface.

3.5. Effect of Ionic Strength. The adsorption of OTC onto sediment samples as a function of ionic strength is shown in Figure 9. The result confirms that the presence of electrolytes such as $\mathrm{NaCl}$ in aqueous solution had a significant negative effect on OTC adsorption onto sediment samples. When the ionic strength of the aqueous solution increased from 0 to $17.11 \mathrm{mmol} / \mathrm{L}$, the OTC adsorption capacity all decreased. For the sampling point 1, it decreased from 1.9432 to $0.4961 \mathrm{mg} / \mathrm{kg}$ while it decreased from 2.1153 to $0.6513 \mathrm{mg} / \mathrm{kg}$ for the sampling point 2 , and for the sampling point 3 , it decreased from 2.3283 to $0.8416 \mathrm{mg} / \mathrm{kg}$.

\section{Conclusion}

The adsorption of OTC onto the sediment samples from the Weihe River got equilibrium in about 24 hours. The adsorption kinetics of OTC onto the sediment samples was found to follow a pseudo-first-order model. The equilibrium adsorption data of OTC fitted well with Langmuir and Freundlich isotherm models. However, the Langmuir isotherm was more suitable to describe the adsorption behavior of OTC onto these sediment samples because it gave a comparatively 
lower error function compared with the Freundlich model. The calculated thermodynamic parameters showed that the adsorption of OTC was feasible, spontaneous, entropy increasing, and endothermic in nature, and the adsorption capacity increased with increasing temperature. The adsorption capacity of OTC did not cause obvious change at solution $\mathrm{pH} 4.0-7.0$, and both decreased with an increase in solution $\mathrm{pH}$ from 7.0 to 10.0 and a decrease in solution $\mathrm{pH}$ from 4.0 to 2.0. The presence of electrolytes such as $\mathrm{NaCl}$ in aqueous solution had a significant negative effect on OTC adsorption onto sediment samples. The mechanisms controlling OTC adsorption onto these sediment samples were supposed to be chemisorption as the equilibrium adsorption data of OTC fitted well with Langmuir isotherm models. However, the calculated thermodynamic parameters indicated that the mechanisms controlling OTC adsorption may involve other sorption forms which needs a further study.

\section{Acknowledgments}

Funding for this study was provided by the National Natural Science Foundation of China (nos. 41072185 and 41072184) and the Central University Special Fund.

\section{References}

[1] S. Q. Cohlan, “Tetracycline staining of teeth,” Teratology, vol. 15, no. 1, pp. 127-129, 1977.

[2] E. L. Francke and H. C. Neu, "Chloramphenicol and tetracyclines," The Medical Clinics of North America, vol. 71, no. 6, pp. 1155-1168, 1987.

[3] G. Cheng, "Interaction of tetracycline with aluminum and iron hydrous oxides," Environmental Science and Technology, vol. 39, pp. 2660-2667, 2005.

[4] S. B. Levy, The Antibiotic Paradox: How the Misuse of Antibiotics Destroys Their Curative Power, Perseus Publishing, Cambridge, Mass, USA, 2002.

[5] Y. X. Liu and Y. Y. Bao, "A review on pollution situation of tetracycline antibiotics in soil environment," Environmental Pollution and Control, vol. 33, pp. 81-86, 2011.

[6] P. Kulshrestha, R. F. Giese, and D. S. Aga, "Investigating the molecular interactions of oxytetracycline in clay and organic matter: insights on factors affecting its mobility in soil," Environmental Science and Technology, vol. 38, no. 15, pp. 4097-4105, 2004.

[7] P. K. Jjemba, “The potential impact of veterinary and human therapeutic agents in manure and biosolids on plants grown on arable land: a review," Agriculture, Ecosystems and Environment, vol. 1918, pp. 1-12, 2002.

[8] S. B. Halling, "Algal toxicity of antibacterial agents used in intensive farming," Chemosphere, vol. 40, no. 7, pp. 731-739, 2000.

[9] Z. J. Li, R. H. Qi, J. Long, F. F. Fan, F. L. Fan, and Y. C. Liang, "Influence of particle size on the adsorption of oxytetracycline on black soil and red soil," Journal of Agro-Environment Science, vol. 29, pp. 2357-2362, 2010.

[10] E. Zuccato, D. Calamari, M. Natangelo, and R. Fanelli, "Presence of therapeutic drugs in the environment," The Lancet, vol. 355, no. 9217, pp. 1789-1790, 2000.
[11] D. W. Kolpin, E. T. Furlong, M. T. Meyer et al., "Pharmaceuticals, hormones, and other organic wastewater contaminants in U.S. streams, 1999-2000: a national reconnaissance," Environmental Science and Technology, vol. 36, no. 6, pp. 1202-1211, 2002.

[12] A. J. Sarmah, M. T. Meyer, and A. B. A. Boxall, "A global perspective on the use, sales, exposure pathways, occurrence, fate and effects of veterinary antibiotics (VAs) in the environment," Chemosphere, vol. 65, no. 5, pp. 725-759, 2006.

[13] P. A. Blackwell, A. B. A. Boxall, P. Kay, and H. Noble, "Evaluation of a lower tier exposure assessment model for veterinary medicines," Journal of Agricultural Food Chemistry, vol. 53, pp. 2192-2201, 2005.

[14] H. M. Qi, L. Lv, and X. L. Qiao, "Progress in sorption of antibiotics to soils," Soils, vol. 41, no. 5, pp. 703-708, 2009.

[15] Y. Y. Bao, Q. X. Zhou, Y. Wan, and X. J. Xie, "Effect of soil organic matter on adsorption and desorption of oxytetracycline in soils," China Environmental Science, vol. 29, no. 6, pp. 651-655, 2009.

[16] R. A. Figueroa, A. Leonard, and A. A. Mackay, "Modeling tetracycline antibiotic sorption to clays," Environmental Science and Technology, vol. 38, no. 2, pp. 476-483, 2004.

[17] Y. Y. Bao, Q. X. Zhou, and H. Zhang, "Influences of cation species on adsorption and desorption of oxytetracycline in two typical soils of China," Environmental Science, vol. 30, no. 2, pp. 551-556, 2009.

[18] F. Yuan, C. Hu, X. Hu, D. Wei, Y. Chen, and J. Qu, "Photodegradation and toxicity changes of antibiotics in UV and $\mathrm{UV} / \mathrm{H}_{2} \mathrm{O}_{2}$ process," Journal of Hazardous Materials, vol. 185, no. 2-3, pp. 1256-1263, 2011.

[19] I. Michael, L. Rizzo, C. S. McArdell et al., "Urban wastewater treatment plants as hotspots for the release of antibiotics in the environment: a review," Water Research, vol. 47, pp. 957-995, 2013.

[20] H. Kang, S. K. Yang, W. K. Wang et al., "Research about adsorption characteristics of $\mathrm{Pb}^{2+}$ on sediments at Weihe river," in Proceedings of the International Symposium on Water Resource and Environmental Protection (ISWREP '11), pp. 1526-1528, May 2011.

[21] P. J. Dillon, M. Miller, H. Fallowfield, and J. Hutson, "The potential of riverbank filtration for drinking water supplies in relation to microsystin removal in brackish aquifers," Journal of Hydrology, vol. 266, no. 3-4, pp. 209-221, 2002.

[22] G. Y. Luo, H. Zhu, X. Y. Xu, W. L. Cai, and J. F. Dou, "Sorption behaviors of polycyclic aromatic hydrocarbon on surface sediment in Chongqing section of the Yangtze River," Environmental Science and Technology, vol. 33, pp. 1-5, 2010.

[23] Z. Y. Guo, X. Y. Hua, D. P. Liang et al., "Sorption characteristic of organochlorine pesticides onto the lighter and heavier components of biofilms, suspended particles and surface sediments in natural water," Chemical Journal of Chinese Universities, vol. 31, no. 5, pp. 919-926, 2010.

[24] J. T. Hu, H. M. Zong, J. Y. Wang, and D. Y. Ma, "Adsorption behaviors of florfenicol on sediment in the ocean," Environmental Chemistry, vol. 27, no. 4, pp. 481-484, 2008.

[25] S. A. Sassman and L. S. Lee, "Sorption of three tetracyclines by several soils: assessing the role of $\mathrm{pH}$ and cation exchange," Environmental Science and Technology, vol. 39, no. 19, pp. 74527459, 2005.

[26] OECD Guidelines for Testing of Chemicals, Test Guideline 106: Adsorption/Desorption Using a batch Equilibrium Method, OECD, Paris, Farnce, 2000. 
[27] A. Ozer, D. Ozer, and H. I. Ekiz, "The equilibrium and kinetic modelling of the biosorption of copper(II) ions on cladophora crispata," Adsorption Journal of the International Adsorption Society, vol. 10, no. 4, pp. 317-326, 2004.

[28] J. W. Lin, Y. H. Zhan, Z. L. Zhu, and Y. Q. Xing, "Adsorption of tannic acid from aqueous solution onto surfactant-modified zeolite," Journal of Hazardous Materials, vol. 193, pp. 102-111, 2011.

[29] J. Y. Zhang, L. P. Liang, L. J. Pu, and L. P. Wang, "Adsorption characteristics of $\mathrm{Cr}$ (VI) by wheat straw including kinetic and thermodynamics analysis," Research of Environmental Sciences, vol. 23, pp. 1547-1552, 2010.

[30] M. A. Wahab, S. Jellali, and N. Jedidi, "Ammonium biosorption onto sawdust: FTIR analysis, kinetics and adsorption isotherms modeling," Bioresource Technology, vol. 101, no. 14, pp. 50705075, 2010.

[31] Y. Q. Zhao, M. Razali, and A. O. Babatunde, "Reuse of aluminum-based water treatment sludge to immobilize a wide range of phosphorus contamination: equilibrium study with different isotherm models," Separation Science and Technology, vol. 42, no. 12, pp. 2705-2721, 2007.

[32] Q. S. Liu, T. Zheng, P. Wang, J. P. Jiang, and N. Li, “Adsorption isotherm, kinetic and mechanism studies of some substituted phenols on activated carbon fibers," Chemical Engineering Journal, vol. 157, no. 2-3, pp. 348-356, 2010.

[33] T. S. Anirudhan and P. Senan, "Adsorption characteristics of cytochrome $\mathrm{C}$ onto cationic Langmuir monolayers of sulfonated poly(glycidylmethacrylate)-grafted cellulose: mass transfer analysis, isotherm modeling and thermodynamics," Chemical Engineering Journal, vol. 168, no. 2, pp. 678-690, 2011.

[34] Y. Yu, Y. Y. Zhuang, Z. H. Wang, and M. Q. Qiu, "Adsorption of water-soluble dyes onto modified resin," Chemosphere, vol. 54, no. 3, pp. 425-430, 2004.

[35] Y. Liu, "Is the free energy change of adsorption correctly calculated?" Journal of Chemical \& Engineering Data, vol. 54, no. 7, pp. 1981-1985, 2009.

[36] Y. H. Li, Z. Di, J. Ding, D. Wu, Z. Luan, and Y. Zhu, "Adsorption thermodynamic, kinetic and desorption studies of $\mathrm{Pb}^{2+}$ on carbon nanotubes," Water Research, vol. 39, no. 4, pp. 605-609, 2005.

[37] M. Sathishkumar, A. R. Binupriya, D. Kavitha et al., "Adsorption potential of maize cob carbon for 2,4-dichlorophenol removal from aqueous solutions: equilibrium, kinetics and thermodynamics modeling," Chemical Engineering Journal, vol. 147, no. 2-3, pp. 265-271, 2009.

[38] K. Sakurai, Y. Ohdate, and K. Kyuma, "Potentiometric automatic titration (PAT) method to evaluate zero point of charge (ZPC) of variable charge soils," Soil Science and Plant Nutrition, vol. 35, no. 1, pp. 89-100, 1989.

[39] W. H. Hendershot, G. A. Singleton, and L. M. Lavkulich, "Variation in surface charge characteristics in a soil chronosequence," Soil Science of America Journal, vol. 43, no. 2, pp. 387-389, 1979.

[40] P. H. Chang, Z. H. Li, W. T. Jiang, and J. S. Jean, "Adsorption and intercalation of tetracycline by swelling clay minerals," Applied Clay Science, vol. 46, pp. 27-36, 2009. 

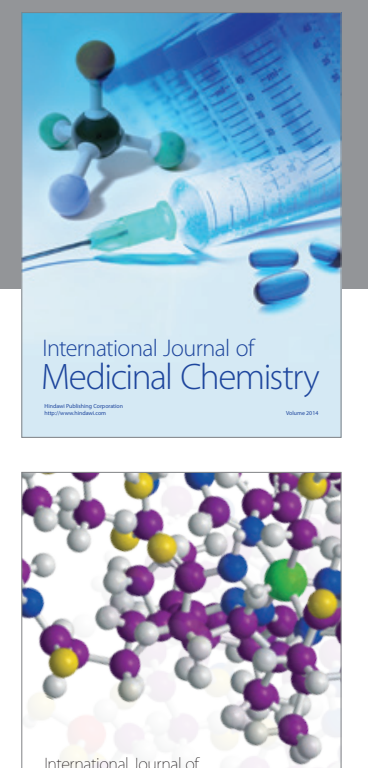

\section{Carbohydrate} Chemistry

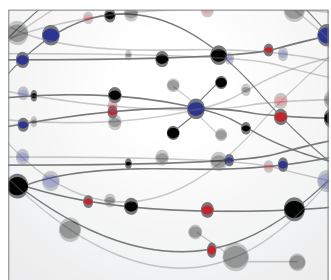

The Scientific World Journal
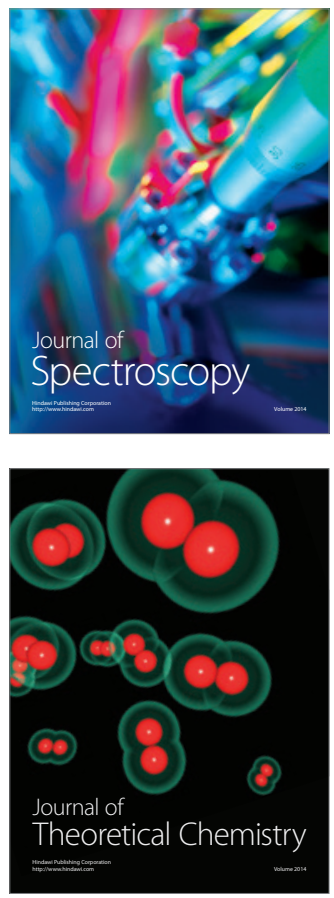
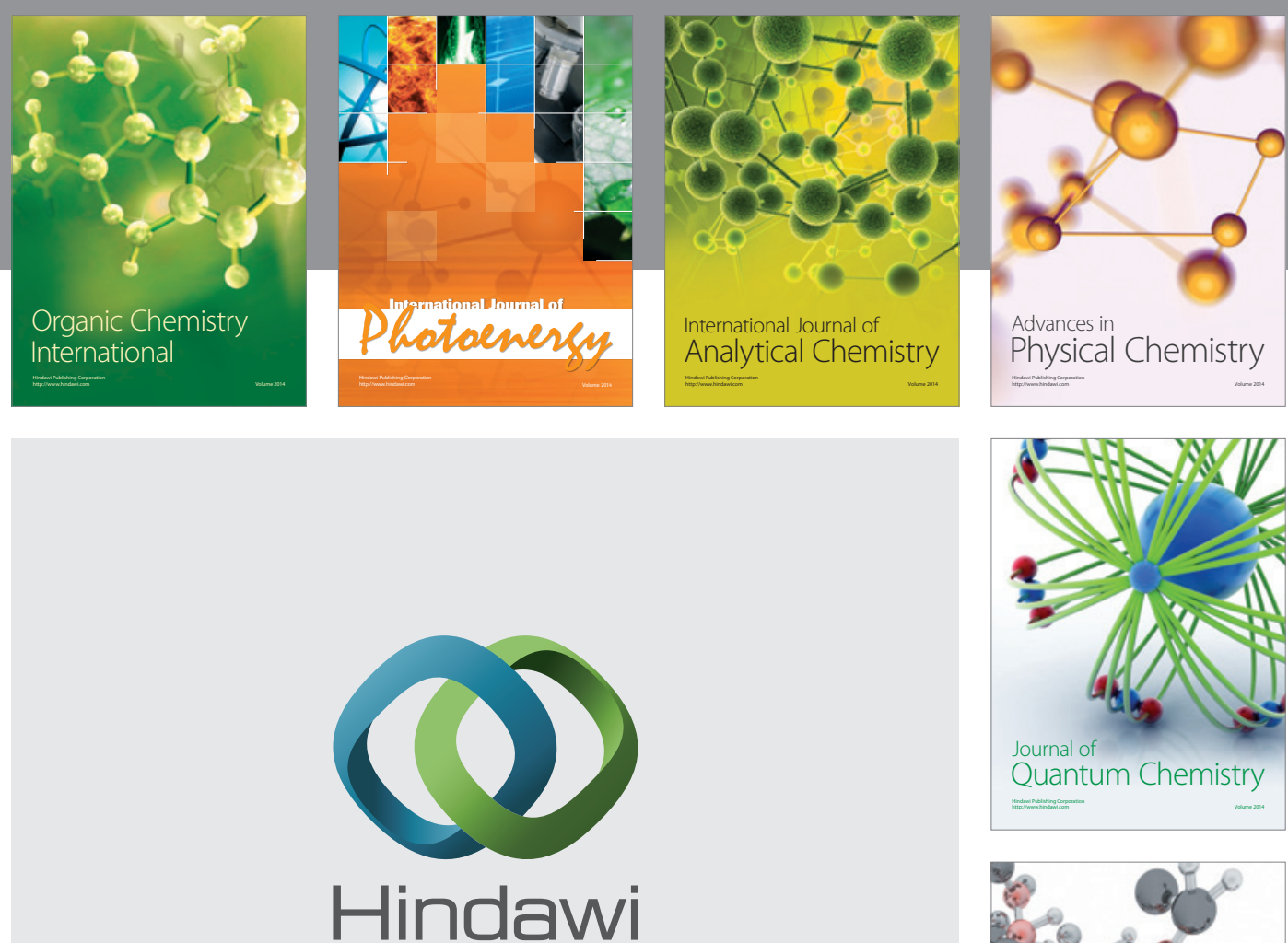

Submit your manuscripts at

http://www.hindawi.com

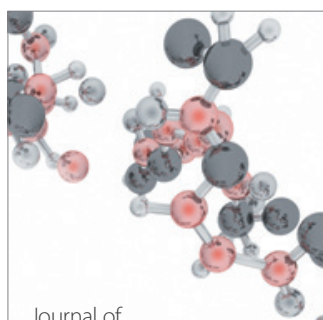

Analytical Methods

in Chemistry

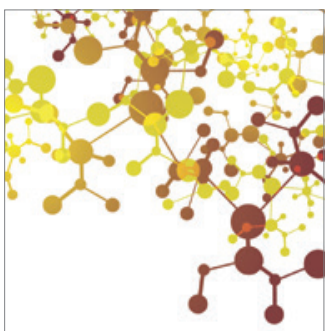

Journal of

Applied Chemistry

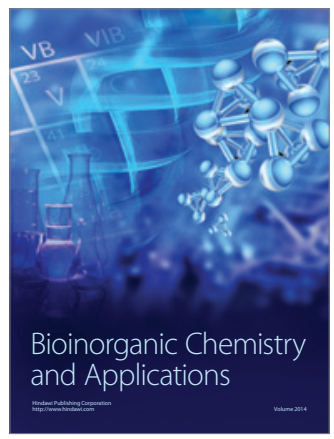

Inorganic Chemistry
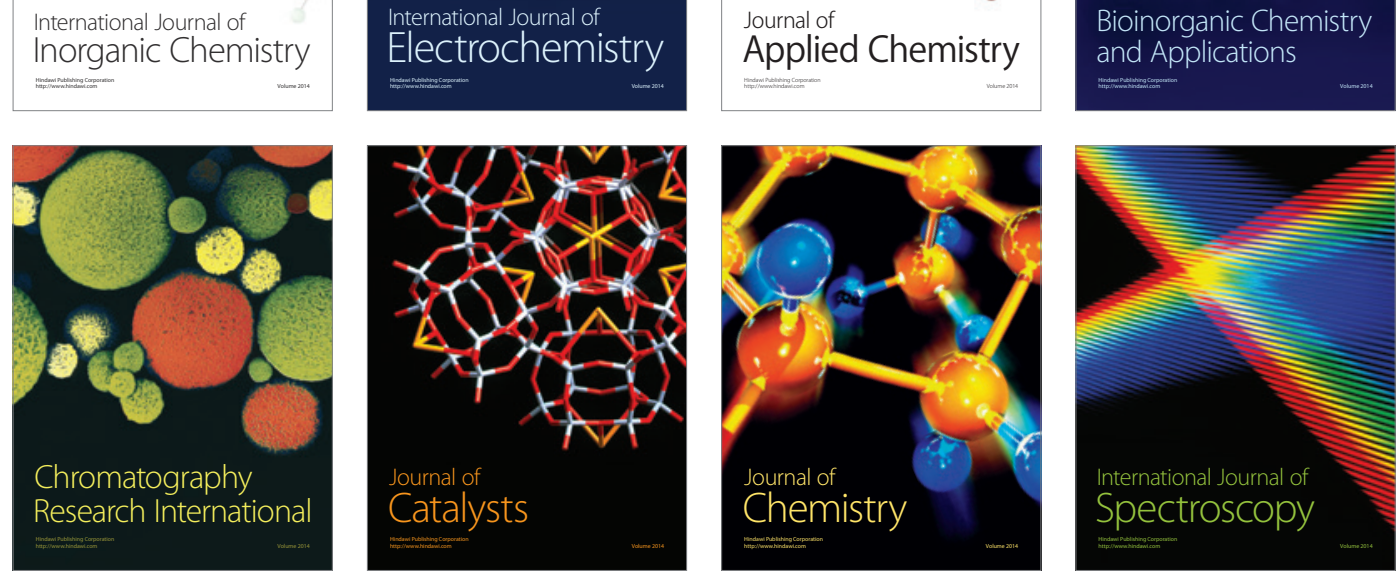